\title{
Physical Activity Coaching Implementation Among Physiotherapists and SCI Peer Mentors: Behavioural Determinants and Effects
}

Hattie Shu

The University of British Columbia https://orcid.org/0000-0001-9984-7794

Kathleen Martin Ginis

The University of British Columbia

Catherine Le Cornu Levett

Vancouver Coastal Health Authority

Chris McBride

Spinal Cord Injury British Columbia

Kristen Walden

Praxis Spinal Cord Institute

Jasmin Ma ( $\nabla$ jasmin.ma@ubc.ca)

University of British Columbia https://orcid.org/0000-0002-0193-4820

Research

Keywords: Exercise, Intervention, Delivery, Adaptation, Uptake, Theory, Knowledge to Action, Quality Implementation Framework

Posted Date: August 17th, 2021

DOl: https://doi.org/10.21203/rs.3.rs-806127/v1

License: (c) (1) This work is licensed under a Creative Commons Attribution 4.0 International License. Read Full License 


\section{Abstract}

\section{Background:}

The most profound drop in physical activity among people with spinal cord injury (SCl) is observed in the months following discharge from rehabilitation. The ProACTIVE SCI intervention has previously demonstrated large-sized effects on physical activity among people with $\mathrm{SCl}$ in the community setting. If implemented successfully during the transition from hospital to community setting, this intervention may help improve physical activity at a critical, yet understudied, timepoint for people with $\mathrm{SCl}$. The purpose of this study is to evaluate the effects of an implementation intervention on physical activity coaching behaviour and its determinants to inform future adaptation of the intervention for sustained implementation.

\section{Methods:}

This study employed a single group, pre-post design. The Knowledge to Action Framework supplemented by the Quality Implementation Framework were used to engage end-users in adapting the intervention and implementation process. The implementation intervention consisted of training (instructions, demonstration, behavioural practice, feedback), provision of educational resources, the addition of a physical activity prompt in patient discharge forms, and engagement of champions. The determinants of physical activity coaching were evaluated using a survey based on the Theoretical Domains Framework (TDF), administered before and immediately following training. Paired two-tailed t-tests were conducted to detect a significant within-subject effect over time on physical activity coaching determinants.

\section{Results:}

A total of ten participants attended training and completed the TDF survey. No significant differences were observed in any of the current physical activity coaching behaviours evaluated during the training period. However, participants reported significant improvements in physical activity coaching behavioural determinants including knowledge, skills, beliefs about capabilities, environmental context and resources, social influences, behavioural regulation, and memory, attention and decision processes ( $p s<0.05)$.

Conclusions: Improvements in determinants signal the potential for changes in physical activity coaching behaviour. Determinant scores that remained low will be targeted to inform the ongoing adaptation of the implementation intervention. This study serves as an example of using the TDF, the Knowledge to Action Framework, and the Quality Implementation Framework to guide adaptation and implementation of an intervention.

Trial Registration: U.S. National Library of Medicine, NCT04493606. Registered 29 July 2020, https://clinicaltrials.gov/ct2/show/NCT04493606

\section{Contributions To The Literature}


- Previous research supports the utility of the ProACTIVE SCI intervention on improving physical activity levels among people with $\mathrm{SCl}$ in the community setting, however little is known about the implementation of this intervention from hospital to community setting.

- This study serves as an example of how to employ the Theoretical Domains Framework, Knowledge to Action Framework, and Quality Implementation Framework to guide the intervention design and adaptation process in a novel setting.

- These findings contribute to the implementation science literature by describing how approaches grounded in theory may be used to aid the adaptation, uptake, and impact of an intervention.

\section{Introduction}

Regular physical activity participation has demonstrated improvements in aerobic fitness, cardiovascular risk, and quality of life among people with $\mathrm{SCl}(1-3)$; however, people with spinal cord injury (SCI) face many challenges and barriers to physical activity participation $(4,5)$. Consequently, people with $\mathrm{SCl}$ are among the most physically inactive segment of society, even when compared to other subsets of individuals living with chronic disease and disability (6). Particularly, there is a profound drop in physical activity among people with $\mathrm{SCl}$ in the months following discharge from rehabilitation $(7,8)$. To address this issue of physical inactivity, 300 physiotherapists, community members with $\mathrm{SCl}$, and university researchers co-developed the ProACTIVE SCI intervention to facilitate physical activity promotion for people with $\mathrm{SCl}(9)$.

The ProACTIVE SCI intervention involves physical activity education, referral to appropriate peer mentors, local programs, and health professionals, and adapted exercise prescription (9). The intervention was originally designed for physiotherapists to deliver, as these potential interventionists are perceived as having the training, time, and confidence needed to help patients with $\mathrm{SCl}$ become more physically active $(10-12)$. Peers with $\mathrm{SCl}$ are another potentially effective group of interventionists (11). Peers bring the lived experience in communicating physical activity advice to those who are newly injured, and have been identified as one of the most credible sources of physical activity information by people with $\mathrm{SCl}(11,13)$. As such, both physiotherapists and peers are targeted as interventionists to deliver the ProACTIVE SCI intervention in this study.

While the ProACTIVE SCI intervention has previously demonstrated large-sized effects on physical activity and fitness among people with $\mathrm{SCl}$ in a researcher-delivered, community setting, it has not been implemented pragmatically by healthcare providers or $\mathrm{SCl}$ peer mentors in the specialized rehabilitation hospital and community settings, respectively (14). To date, interventions designed to enhance physical activity participation among individuals with $\mathrm{SCl}$ are lacking adequate methods to support implementation in the transition from clinical to community settings (15). In order to support implementation success and sustainability in these settings, there is a need to tailor the ProACTIVE intervention and engage end-users in the implementation intervention development process (16-19). This study used the Knowledge to Action (KTA) framework to contextualize the broad phases of intervention adaptation and implementation that were targeted for end-user engagement (16). The Quality 
Implementation Framework (QIF) and Tool, which outlines specific actionable steps for implementation, was used in complement to guide the planning, monitoring and evaluation of ProACTIVE SCI intervention implementation $(20,21)$. The purpose of this study was to evaluate the effects of an implementation intervention on physical activity coaching behaviour and its determinants to inform future adaptation of the intervention.

\section{Methods}

\section{Participants}

This study is powered to detect a significant within-subject effect over time on the TDF measures. When using within subject pre-post analyses, our previous evaluation of the ProACTIVE training amongst physiotherapists demonstrated a very large effect size when averaged across TDF outcomes $(d=1.7)(9)$. A minimum of five participants are needed to yield a significant effect of this magnitude in a withinsubject, repeated measures ANOVA (4 time points), with $\boldsymbol{\beta}=.80, \mathrm{a}=.05$, and a conservative 0.25 correlation among repeated measures. It should be noted that this paper includes only the first two time points of data collection. The protocol of the full study is reported elsewhere (22).

Participants were recruited through email from GF Strong Rehabilitation Hospital and SCI BC in Vancouver, Canada, from June 2019 to January 2020. Specifically, the GF Strong clinical practice coordinator (CLCL) and executive director of SCI BC (CM) invited relevant staff physiotherapists and SCI $\mathrm{BC}$ peer mentors to participate. GF Strong is British Columbia's largest rehabilitation hospital, providing inpatient, outpatient, outreach and clinical support services. SCI BC serves as a major non-profit organization in the province that supports people with $\mathrm{SCl}$. Within $\mathrm{SCI} \mathrm{BC}, \mathrm{SCl} \mathrm{BC}$ peer mentors are individuals with $\mathrm{SCl}$ who have been trained to provide peer support, education, and information resources to others with SCl. Given the pragmatic focus of this study, all interested physiotherapists at GF Strong who worked on the spine unit were recruited, and SCI BC peer mentors were recruited by the executive director based on availability, coaching skills, training, and geographical location. Ethics approval for the protocol was granted by the Behavioural Research Ethics Board at the University of British Columbia (H19-02694). Written informed consent was obtained from each of the participants. This study was performed in accordance with the standards of ethics outlined in the Declaration of Helsinki.

\section{Study design}

This study employed a single-group, pre-post design. GF Strong physiotherapists and SCI BC Peers received two in-person training sessions on how to implement the ProACTIVE SCI intervention. The two training sessions were each two hours in length, and administered over two days, separated by four weeks. Between training sessions, interventionists were instructed to practice delivering the ProACTIVE $\mathrm{SCl}$ intervention. A 20-minute survey was administered prior to the first training session and immediately after the second training session. All procedures were conducted at GF Strong Rehabilitation Hospital or if the questionnaire was completed online, this was done in the setting of the participant's choosing. 


\section{Measures}

\section{Demographics}

Participant demographics were collected using an online form and included age, sex, role (in-patient physiotherapist, out-patient physiotherapist, or SCI Peer), and years of experience in their role.

Implementation Survey

Participants completed an online or paper survey to identify barriers and facilitators (determinants) to physical activity coaching. The Determinants of Implementation Behaviour Questionnaire (DIBQ) was used to inform the content of the survey $(23,24)$. The DIBQ is a Theoretical Domains Framework (TDF)based questionnaire, of which support for the internal consistency, reliability and discriminant validity of the DIBQ has been demonstrated among physiotherapists previously (24). The TDF identifies 14 domains or behavioural determinants that resulted from a synthesis of 128 theoretical constructs from 33 behaviour change theories $(23,25)$. Physical activity coaching determinants (e.g. "I know how to educate my clients on how to be physically active") were evaluated using a 7-point Likert scale, where 1 = strongly disagree and 7 = strongly agree. Response options also included the ability to select "not applicable"; these responses were not included in the analysis. To address clinician time constraints, the DIBQ was shortened from its original 93 items to 32 items in consultation with stakeholders during pilot-testing. Additionally, the TDF domains of optimism and emotion were removed, as pilot-testing feedback suggested these domains were not relevant. The survey also included a 7-item evaluation of the effects of the implementation intervention on interventionist physical activity coaching behaviour (e.g. "I currently use the ProACTIVE SCI Toolkit with my clients"). Current behaviour was evaluated using a 5point Likert scale, where $1=$ never and $5=$ always.

\section{Adaptation of the ProACTIVE SCI intervention to the local context}

Over a six-month timeframe prior to study commencement, the team worked to systematically address the steps of the KTA and QIF frameworks and adapt the ProACTIVE SCI intervention. Specifically, the KTA was used to guide the phases of the research process in which both researchers and end-users (physiotherapists and peers with $\mathrm{SCl}$ ) could be involved to adapt the ProACTIVE intervention content and its implementation. The QIF action steps were re-ordered for our local context and used to guide the execution of KTA phases (Table 1). For a detailed description of the step-by-step process used in this study, see Additional file 1. 
Table 1

Quality Implementation Framework action steps used to guide the execution of the Knowledge to Action framework phases

\begin{tabular}{|c|c|}
\hline KTA phase & QIF action step in order of use \\
\hline $\begin{array}{l}\text { Knowledge } \\
\text { synthesis }\end{array}$ & $\mathrm{N} / \mathrm{A}$ \\
\hline \multirow{9}{*}{$\begin{array}{l}\text { Problem } \\
\text { identification }\end{array}$} & 1.2 Identify an implementation team leader \\
\hline & 1.3 Identify and recruit content area specialists as team members \\
\hline & $\begin{array}{l}1.4 \text { Identify and recruit other agencies and/or community members such as } \\
\text { family members, youth, clergy, and business leaders as team members }\end{array}$ \\
\hline & 4.2 Identify and foster relationship with a trainer(s) and/or TA provider(s) \\
\hline & 1.5 Assign team members roles, processes, and responsibilities \\
\hline & 2.1 Identify and foster a relationship with a champion for the innovation \\
\hline & $\begin{array}{l}\text { 1.1 Decide on structure of team overseeing implementation (e.g., steering } \\
\text { committee, advisory board, community coalition, workgroups, etc.) }\end{array}$ \\
\hline & $\begin{array}{l}2.2 \text { Communicate the perceived need for the innovation within the } \\
\text { organization/community }\end{array}$ \\
\hline & $\begin{array}{l}2.3 \text { Communicate the perceived benefit of the innovation within the } \\
\text { organization/community }\end{array}$ \\
\hline $\begin{array}{l}\text { Identify, review, } \\
\text { select knowledge }\end{array}$ & $\mathrm{N} / \mathrm{A}$ \\
\hline $\begin{array}{l}\text { Adapt knowledge } \\
\text { to the local context }\end{array}$ & $\mathrm{N} / \mathrm{A}$ \\
\hline \multirow{5}{*}{$\begin{array}{l}\text { Assess } \\
\text { barriers/facilitators } \\
\text { to knowledge use }\end{array}$} & 4.1 Determine specific needs for training and/or technical assistance (TA) \\
\hline & 2.4 Establish practices that counterbalance stakeholder resistance to change \\
\hline & 2.5 Create policies that enhance accountability \\
\hline & $\begin{array}{l}\text { 2.6 Create policies that foster shared decision-making and effective } \\
\text { communication }\end{array}$ \\
\hline & 2.7 Ensure that the program has adequate administrative support \\
\hline
\end{tabular}

Note. KTA = Knowledge to Action Framework (16), QIF = Quality Implementation Framework $(20,21)$ 


\begin{tabular}{|c|c|}
\hline KTA phase & QIF action step in order of use \\
\hline \multirow{6}{*}{$\begin{array}{l}\text { Select, tailor, } \\
\text { implement } \\
\text { interventions }\end{array}$} & 3.1 List tasks required for implementation \\
\hline & 3.2 Establish a timeline for implementation tasks \\
\hline & 3.3 Assign implementation tasks to specific stakeholders \\
\hline & $\begin{array}{l}\text { 4.3 Ensure that trainer(s) and/or TA provider(s) have sufficient knowledge } \\
\text { about the organization/community's needs and resources }\end{array}$ \\
\hline & $\begin{array}{l}\text { 4.4 Ensure that trainer(s) and/or TA provider(s) have sufficient knowledge } \\
\text { about the organization/community's goals and objectives }\end{array}$ \\
\hline & 4.5 Work with TA providers to implement the innovation \\
\hline \multirow[t]{8}{*}{$\begin{array}{l}\text { Monitor knowledge } \\
\text { use }\end{array}$} & $\begin{array}{l}5.1 \text { Collaborate with expert developers (e.g., researchers) about factors } \\
\text { impacting quality of implementation in the organization/community }\end{array}$ \\
\hline & 6.1 Measure fidelity of implementation (i.e., adherence, integrity) \\
\hline & $\begin{array}{l}6.2 \text { Measure dosage of the innovation-how much of the innovation was } \\
\text { actually delivered }\end{array}$ \\
\hline & $\begin{array}{l}\text { 6.3 Measure quality of the innovation's delivery-qualitative aspects of } \\
\text { program delivery (e.g., implementer enthusiasm, leader preparedness, global } \\
\text { estimates of session effectiveness, leader attitudes towards the innovation) }\end{array}$ \\
\hline & $\begin{array}{l}\text { 6.4 Measure participant responsiveness to the implementation process- } \\
\text { degree to which participants are engaged in the activities and content of the } \\
\text { innovation }\end{array}$ \\
\hline & $\begin{array}{l}\text { 6.5 Measure degree of program differentiation-extent to which the targeted } \\
\text { innovation differs from other innovations in the organization/community }\end{array}$ \\
\hline & $\begin{array}{l}\text { 6.6 Measure program reach-extent to which the innovation is delivered to the } \\
\text { people it was designed to reach }\end{array}$ \\
\hline & $\begin{array}{l}\text { 6.7 Document all adaptations that are made to the innovation-extent to which } \\
\text { adjustments were made to the original innovation or program in order to fit the } \\
\text { host setting's needs, resources, preferences, or other important characteristics }\end{array}$ \\
\hline Evaluate outcomes & N/A \\
\hline $\begin{array}{l}\text { Sustain Knowledge } \\
\text { Use }\end{array}$ & 5.2 Engage in problem solving \\
\hline \multicolumn{2}{|c|}{ Note. KTA = Knowledge to Action Framework (16), QIF = Quality Implementation Framework $(20,21)$} \\
\hline
\end{tabular}

Briefly, prior to the study commencement, a core implementation team was developed including researchers (JM, HS, KMG), a clinical consultant (KW), a hospital physiotherapy practice coordinator (CLCL), and the executive director of the provincial SCl support organization (CM). The core implementation team worked to iteratively adapt the ProACTIVE SCI intervention and its implementation methods to meet the needs of the local context in the hospital and community settings. Six meetings were held amongst the core implementation team to discuss guiding principles for communication, goals of the project, additional team members needed, barriers and facilitators to implementation, training 
needs, and timelines and tasks. Two hospital physiotherapists (in-patient and out-patient) and a trained peer support provider from a SCl-focussed community service organization were recruited as champions to facilitate the adaptation and adoption of the intervention.

Four additional meetings were conducted with participating GF Strong physiotherapists and SCI BC peer interventionists to communicate the perceived need and benefit of the intervention, review the intervention content and implementation intervention procedure, and identify additional supporting documents for implementation. Supporting documents were created, and included an aerobic and strength training prescription guide, tailored forms to document coaching conversations with physiotherapists and $\mathrm{SCl}$ Peers, and an exercise intensity chart adapted for clients with SCl. Iterative drafts of the implementation intervention procedure and supporting documents were circulated amongst the GF Strong physiotherapists and $\mathrm{SCI} B C$ peers until all stakeholders were satisfied. The FRAME framework was used to document the adaptations made to the implementation process and is reported in Additional file 2 (26, 27). Lastly, the primary investigator (JM) established a temporary office at the hospital site, making herself accessible to physiotherapists and $\mathrm{SCl}$ peers for informal communications important for adapting the intervention content and implementation.

\section{Implementation intervention}

The implementation intervention has been described in detail previously (22). Briefly, the implementation intervention consisted of two training sessions (see Additional file 3 for training slides), provision of the ProACTIVE SCI intervention toolkit (https://sciactioncanada.ok.ubc.ca/resources/proactive-sci-toolkit/), resources to guide physical activity prescription and document the coaching conversation (see Additional file 4), the addition of a physical activity prompt in patient discharge forms, and engagement of clinician and peer champions. During the four weeks following the first training session, the interventionists were instructed to practice delivering the ProACTIVE SCI intervention in the clinical or community setting.

\section{Statistical analyses}

Descriptive statistics were used to summarize demographic data, and paired, two-tailed t-tests were used to detect a significant within-subject effect from pre- to post-training on the TDF implementation survey data. All TDF survey implementation data were reported by mean and standard deviation, and current behaviour findings were further dichotomized by combining "usually" or "always" responses into one category, and "never", "seldom", or "about half the time" responses into another. Internal consistency of TDF domains was assessed using Cronbach's alpha. Only the domain, environmental context and resources - innovation strategy, showed acceptable internal consistency (Cronbach's alpha >0.7) across its three items in both pre- and post- implementation scores. All other domains with three or more items, did not show acceptable internal consistency (Cronbach's alpha $<0.7$ ) across its items in both pre- and post- implementation. Consequently, item scores for all TDF domains, with the exception of environmental context and resources - innovation strategy, were not averaged to provide an aggregate score, and individual physical activity coaching determinants were analyzed for significant within-subject effects from pre- to post-training using Bonferroni-adjusted alpha levels. 


\section{Results}

\section{Demographics}

Of the 13 potential participants, all of them attended the training sessions. Ten of the attendees completed the implementation surveys administered prior to the first training session, and immediately after the second training session. Survey respondent demographics are presented in Table 2. The majority of participants were physiotherapists specializing in in-patient care $(n=6$; out-patient $n=2)$. The remaining participants were $S C I B C$ peers $(n=2)$. The age of participants varied, with most of the participants aged $30-39$ years $(n=3)$ or $40-49$ years $(n=3)$. Participants were primarily female $(n=9)$, and had worked in their respective roles for an average of $16.95 \pm 12.68$ years.

Table 2

Interventionist demographics

\begin{tabular}{|ll|}
\hline Variable & $\mathbf{n}(\%)$ \\
\hline Role & $2(20)$ \\
\hline SCI BC Peer & $6(60)$ \\
\hline In-patient physiotherapist & $2(20)$ \\
\hline Out-patient physiotherapist & \\
\hline Age (y) & $1(10)$ \\
\hline $20-29$ & $3(30)$ \\
\hline $30-39$ & $3(30)$ \\
\hline $40-49$ & $2(20)$ \\
\hline $50-59$ & $1(10)$ \\
\hline $60+$ & \\
\hline Gender & $9(90)$ \\
\hline Female & $1(10)$ \\
\hline Male & $16.95(12.68)^{\#}$ \\
\hline Years in role (y) & \\
\hline Note. Presented as mean (SD). SCl = Spinal Cord Injury \\
\hline
\end{tabular}

\section{Current physical activity coaching behaviour}

The following describes 'usually' or 'always' responses to current physical activity coaching behaviour among interventionists. For responses recoded as numerical values and summarized as means and SD, 
see Table 3. Prior to the implementation intervention, none of the interventionists used the ProACTIVE SCI Toolkit with their clients, referred their clients to the SCI BC InfoLine for physical activity information, or prescribed a physical activity program for their clients (outside of rehabilitative exercise). Few participants used the $\mathrm{SCl}$ physical activity guidelines with their clients $(10 \%)$, or referred their clients to SCI BC peers for physical activity information (20\%). Half of the participants educated their clients on what physical activity is and the benefits of being physically active (outside of rehabilitative exercise). Most participants referred their clients to physical activity programs/organizations (60\%). T-tests using recoded numerical values revealed that immediately following the implementation intervention (i.e., reporting on behaviour during the practice period between trainings), no significant differences were observed in any of the current physical activity coaching behaviour areas ( $p s>0.05$; Table 3 ).

Table 3

Current physical activity coaching behaviour among interventionists

\begin{tabular}{|c|c|c|c|c|c|c|}
\hline & $\begin{array}{l}\text { "Alw } \\
\text { "Usu } \\
\text { n (\%) }\end{array}$ & $\begin{array}{l}\text { s" or } \\
\text { ly" }\end{array}$ & Mean & & & \\
\hline Question Statement & Pre & Post & Pre & Post & $\begin{array}{l}\text { p- } \\
\text { value }\end{array}$ & $\begin{array}{l}\text { Cohen's } \\
\text { d }\end{array}$ \\
\hline $\begin{array}{l}\text { I currently use the ProACTIVE SCI Toolkit with } \\
\text { my clients. }\end{array}$ & $\begin{array}{l}0 \\
(0)\end{array}$ & $0(0)$ & $\begin{array}{l}1.3 \\
(0.67)\end{array}$ & $\begin{array}{l}1.7 \\
(0.71)\end{array}$ & 0.08 & 0.53 \\
\hline $\begin{array}{l}\text { I currently use the } \mathrm{SCl} \text { physical activity } \\
\text { guidelines with my clients. }\end{array}$ & $\begin{array}{l}1 \\
(10)\end{array}$ & $\begin{array}{l}1 \\
(11)\end{array}$ & $\begin{array}{l}2.3 \\
(1.06)\end{array}$ & $\begin{array}{l}2.3 \\
(0.87)\end{array}$ & 0.68 & 0.03 \\
\hline $\begin{array}{l}\text { I educate my clients on what physical activity } \\
\text { is and the benefits of being physically active } \\
\text { (outside of rehabilitative exercise). }\end{array}$ & $\begin{array}{l}5 \\
(50)\end{array}$ & $\begin{array}{l}6 \\
(60)\end{array}$ & $\begin{array}{l}3.6 \\
(0.97)\end{array}$ & $\begin{array}{l}3.6 \\
(1.26)\end{array}$ & 1.00 & 0.00 \\
\hline $\begin{array}{l}\text { I refer my clients to physical activity } \\
\text { programs/organizations. }\end{array}$ & $\begin{array}{l}6 \\
(60)\end{array}$ & $\begin{array}{l}7 \\
(70)\end{array}$ & $\begin{array}{l}3.6 \\
(0.84)\end{array}$ & $\begin{array}{l}3.4 \\
(1.07)\end{array}$ & 0.34 & -0.21 \\
\hline $\begin{array}{l}\text { I refer my clients to SCI BC peers for physical } \\
\text { activity information. }\end{array}$ & $\begin{array}{l}2 \\
(20)\end{array}$ & $\begin{array}{l}2 \\
(20)\end{array}$ & $\begin{array}{l}2.5 \\
(1.08)\end{array}$ & $\begin{array}{l}2.7 \\
(1.34)\end{array}$ & 0.66 & 0.16 \\
\hline $\begin{array}{l}\text { I refer my clients to the } \mathrm{SCI} B C \text { InfoLine for } \\
\text { physical activity information. }\end{array}$ & $\begin{array}{l}0 \\
(0)\end{array}$ & $0(0)$ & $\begin{array}{l}1.5 \\
(0.53)\end{array}$ & $\begin{array}{l}1.6 \\
(0.53)\end{array}$ & 1.00 & 0.11 \\
\hline $\begin{array}{l}\text { I prescribe a physical activity program for my } \\
\text { clients (outside of rehabilitative exercise). }\end{array}$ & $\begin{array}{l}0 \\
(0)\end{array}$ & $\begin{array}{l}1 \\
(11)^{*}\end{array}$ & $\begin{array}{l}2.2 \\
(0.63)\end{array}$ & $\begin{array}{l}2.3 \\
(1.00)\end{array}$ & 1.00 & 0.16 \\
\hline
\end{tabular}

Note. Items evaluated on 5-point Likert Scale, where $1=$ never and $5=$ always; $\mathrm{p}$-value was determined from t-test of numerical scores. $\mathrm{SCl}=\mathrm{Spinal}$ Cord Injury, $\mathrm{BC}=$ British Columbia

\section{Determinants of physical activity coaching behaviour}

Participants reported a significant improvement in determinant scores on 10 of 32 items from pre- to post-implementation intervention (Table 4). These included higher scores from pre- to post-training in the 
TDF domains of knowledge, skills, beliefs about capabilities, environmental context and resources, social influences, behavioural regulation, and memory, attention and decision processes that were statistically significant using Bonferroni-adjusted alpha levels. Environmental context and resources - innovation strategy demonstrated significant improvements in its individual item analysis as well as in its aggregated form (Mean $\mathrm{Pre}=4.2(1.23)$, Mean $\left._{\text {Post }}=5.7(1.11), \mathrm{p}<0.001, d=1.26\right)$. 
Table 4

Determinants of physical activity coaching among interventionists

Mean (SD)

\begin{tabular}{|c|c|c|c|c|c|}
\hline TDF Domain & Question Statement & Pre & Post & p-value & $\begin{array}{l}\text { Cohen's } \\
\text { d }\end{array}$ \\
\hline \multirow[t]{3}{*}{ Knowledge } & $\begin{array}{l}\text { I know how to educate my clients on how } \\
\text { to be physically active. }\end{array}$ & $\begin{array}{l}5.4 \\
(0.97)\end{array}$ & $\begin{array}{l}5.9 \\
(0.74)\end{array}$ & 0.05 & 0.58 \\
\hline & $\begin{array}{l}\text { I know where I can refer my clients to } \\
\text { participate in community physical activity } \\
\text { opportunities. }\end{array}$ & $\begin{array}{l}5.2 \\
(1.40)\end{array}$ & $\begin{array}{l}5.7 \\
(0.82)\end{array}$ & 0.18 & 0.44 \\
\hline & $\begin{array}{l}\text { I know how to design an exercise } \\
\text { prescription for my clients (for fitness- } \\
\text { enhancing purposes not for } \\
\text { rehabilitation). }\end{array}$ & $\begin{array}{l}4.5 \\
(1.51)\end{array}$ & $\begin{array}{l}5.7 \\
(0.50)\end{array}$ & $0.008^{*}$ & 1.04 \\
\hline Skills & $\begin{array}{l}\text { I have the skills to deliver physical activity } \\
\text { coaching. }\end{array}$ & $\begin{array}{l}4.4 \\
(1.71)\end{array}$ & $\begin{array}{l}5.4 \\
(0.97)\end{array}$ & $0.03^{*}$ & 0.72 \\
\hline $\begin{array}{l}\text { Social/ } \\
\text { professional } \\
\text { role and } \\
\text { identity }\end{array}$ & $\begin{array}{l}\text { Delivering physical activity coaching is a } \\
\text { part of my professional role. }\end{array}$ & $\begin{array}{l}4.9 \\
(1.79)\end{array}$ & $\begin{array}{l}5.5 \\
(1.08)\end{array}$ & 0.17 & 0.41 \\
\hline \multirow[t]{3}{*}{$\begin{array}{l}\text { Beliefs about } \\
\text { capabilities }\end{array}$} & $\begin{array}{l}\text { I am confident that I can deliver physical } \\
\text { activity coaching effectively. }\end{array}$ & $\begin{array}{l}4.8 \\
(1.55)\end{array}$ & $\begin{array}{l}5.6 \\
(0.84)\end{array}$ & 0.07 & 0.64 \\
\hline & $\begin{array}{l}\text { I am confident that I can deliver physical } \\
\text { activity coaching even when there is little } \\
\text { time. }\end{array}$ & $\begin{array}{l}4.0 \\
(1.41)\end{array}$ & $\begin{array}{l}4.8 \\
(1.32)\end{array}$ & 0.10 & 0.59 \\
\hline & $\begin{array}{l}\text { I am confident that I can deliver physical } \\
\text { activity coaching even when clients are } \\
\text { not motivated. }\end{array}$ & $\begin{array}{l}3.6 \\
(1.17)\end{array}$ & $\begin{array}{l}4.9 \\
(0.88)\end{array}$ & $0.009 *$ & 1.26 \\
\hline BAC- Attitudes & $\begin{array}{l}\text { For me, delivering physical activity } \\
\text { coaching is worthwhile. }\end{array}$ & $\begin{array}{l}5.8 \\
(1.32)\end{array}$ & $\begin{array}{l}6.0 \\
(0.82)\end{array}$ & 0.51 & 0.18 \\
\hline $\begin{array}{l}\text { BAC- Outcome } \\
\text { expectancies }\end{array}$ & $\begin{array}{l}\text { If I deliver physical activity coaching } \\
\text { sessions, I will help my clients be more } \\
\text { physically active. }\end{array}$ & $\begin{array}{l}5.7 \\
(1.06)\end{array}$ & $\begin{array}{l}5.8 \\
(0.63)\end{array}$ & 0.68 & 0.11 \\
\hline $\begin{array}{l}\text { BAC- } \\
\text { Reinforcement }\end{array}$ & $\begin{array}{l}\text { When/if I deliver physical activity } \\
\text { coaching sessions, I get recognition or } \\
\text { praise from the work context. }\end{array}$ & $\begin{array}{l}3.7 \\
(1.25)\end{array}$ & $\begin{array}{l}4.6 \\
(1.13)\end{array}$ & 0.17 & 0.72 \\
\hline
\end{tabular}

Note. Items evaluated on 7-point Likert Scale, where 1 = strongly disagree and 7 = strongly agree. BAC = Beliefs about consequences; $\mathrm{ECR}=$ Environmental Context and Resources; MADP = Memory, Attention, and Decision Processes; $\mathrm{SCl}=$ Spinal Cord Injury.

*Indicates significant difference between pre- and post-test using Bonferroni-adjusted alpha levels. 


\begin{tabular}{|c|c|c|c|c|c|}
\hline & \multirow[b]{2}{*}{$\begin{array}{l}\text { When/if I deliver physical activity } \\
\text { coaching sessions, I get recognition or } \\
\text { praise from my clients. }\end{array}$} & \multicolumn{4}{|c|}{ Mean (SD) } \\
\hline & & $\begin{array}{l}4.1 \\
(0.69)\end{array}$ & $\begin{array}{l}4.9 \\
(0.69)\end{array}$ & 0.24 & 1.04 \\
\hline Intentions & $\begin{array}{l}\text { I will definitely deliver physical activity } \\
\text { coaching sessions guided by the } \\
\text { ProACTIVE SCl intervention in the next } \\
\text { three months. }\end{array}$ & $\begin{array}{l}5.6 \\
(1.17)\end{array}$ & $\begin{array}{l}5.8 \\
(1.03)\end{array}$ & 0.56 & 0.18 \\
\hline Goals & $\begin{array}{l}\text { Physical activity coaching is a higher } \\
\text { priority than my other work duties. }\end{array}$ & $\begin{array}{l}2.2 \\
(0.92)\end{array}$ & $\begin{array}{l}3.0 \\
(1.25)\end{array}$ & 0.10 & 0.73 \\
\hline \multirow[t]{5}{*}{$\begin{array}{l}\text { ECR- } \\
\text { Innovation }\end{array}$} & $\begin{array}{l}\text { It is possible to tailor physical activity } \\
\text { coaching to clients' needs. }\end{array}$ & $\begin{array}{l}6.1 \\
(0.74)\end{array}$ & $\begin{array}{l}6.1 \\
(0.88)\end{array}$ & 1 & 0 \\
\hline & $\begin{array}{l}\text { It takes little time to deliver physical } \\
\text { activity coaching. }\end{array}$ & $\begin{array}{l}4.2 \\
(1.20)\end{array}$ & $\begin{array}{l}4.6 \\
(1.67)\end{array}$ & 0.63 & 0.23 \\
\hline & $\begin{array}{l}\text { Physical activity coaching is compatible } \\
\text { with my work context. }\end{array}$ & $\begin{array}{l}5.3 \\
(0.95)\end{array}$ & $\begin{array}{l}4.8 \\
(1.62)\end{array}$ & 0.14 & -0.38 \\
\hline & $\begin{array}{l}\text { Physical activity coaching is simple to } \\
\text { deliver. }\end{array}$ & $\begin{array}{l}4.1 \\
(1.05)\end{array}$ & $\begin{array}{l}4.7 \\
(1.66)\end{array}$ & 0.18 & 0.40 \\
\hline & $\begin{array}{l}\text { Physical activity coaching is effective for } \\
\text { supporting my clients to improve their } \\
\text { physical activity participation. }\end{array}$ & $\begin{array}{l}5.4 \\
(1.01)\end{array}$ & $\begin{array}{l}6.0 \\
(0.67)\end{array}$ & 0.14 & 0.65 \\
\hline $\begin{array}{l}\text { ECR- Socio- } \\
\text { political } \\
\text { context }\end{array}$ & $\begin{array}{l}\text { Government and local authorities provide } \\
\text { sufficient support for physical activity } \\
\text { coaching. }\end{array}$ & $\begin{array}{l}2.2 \\
(0.97)\end{array}$ & $\begin{array}{l}3.6 \\
(0.84)\end{array}$ & $0.002^{\star}$ & 1.51 \\
\hline \multirow[t]{2}{*}{$\begin{array}{l}\text { ECR- } \\
\text { Organization }\end{array}$} & $\begin{array}{l}\text { The organization I work for provides me } \\
\text { with all the necessary resources to deliver } \\
\text { physical activity coaching. }\end{array}$ & $\begin{array}{l}4.2 \\
(1.32)\end{array}$ & $\begin{array}{l}4.8 \\
(1.03)\end{array}$ & 0.22 & 0.51 \\
\hline & $\begin{array}{l}\text { The management of the organization I } \\
\text { work in supports me in delivering physical } \\
\text { activity coaching. }\end{array}$ & $\begin{array}{l}5.3 \\
(1.06)\end{array}$ & $\begin{array}{l}5.5 \\
(1.08)\end{array}$ & 0.44 & 0.19 \\
\hline ECR-Patient & $\begin{array}{l}\text { Clients that I work with are motivated to } \\
\text { be physically active. }\end{array}$ & $\begin{array}{l}4.2 \\
(1.03)\end{array}$ & $\begin{array}{l}4.1 \\
(1.45)\end{array}$ & 0.76 & -0.08 \\
\hline \multirow{2}{*}{$\begin{array}{l}\text { ECR- } \\
\text { Innovation } \\
\text { strategy }\end{array}$} & $\begin{array}{l}\text { I have received sufficient training to } \\
\text { deliver physical activity coaching. }\end{array}$ & $\begin{array}{l}3.7 \\
(1.22)\end{array}$ & $\begin{array}{l}5.6 \\
(0.97)\end{array}$ & $0.0007 *$ & 1.75 \\
\hline & $\begin{array}{l}\text { I have sufficient materials and resources } \\
\text { to deliver physical activity coaching. }\end{array}$ & $\begin{array}{l}4.2 \\
(1.20)\end{array}$ & $\begin{array}{l}5.6 \\
(1.42)\end{array}$ & 0.05 & 1.01 \\
\hline
\end{tabular}

Note. Items evaluated on 7-point Likert Scale, where 1 = strongly disagree and 7 = strongly agree. BAC = Beliefs about consequences; $\mathrm{ECR}=$ Environmental Context and Resources; MADP = Memory, Attention, and Decision Processes; $\mathrm{SCl}=$ Spinal Cord Injury.

*Indicates significant difference between pre- and post-test using Bonferroni-adjusted alpha levels. 


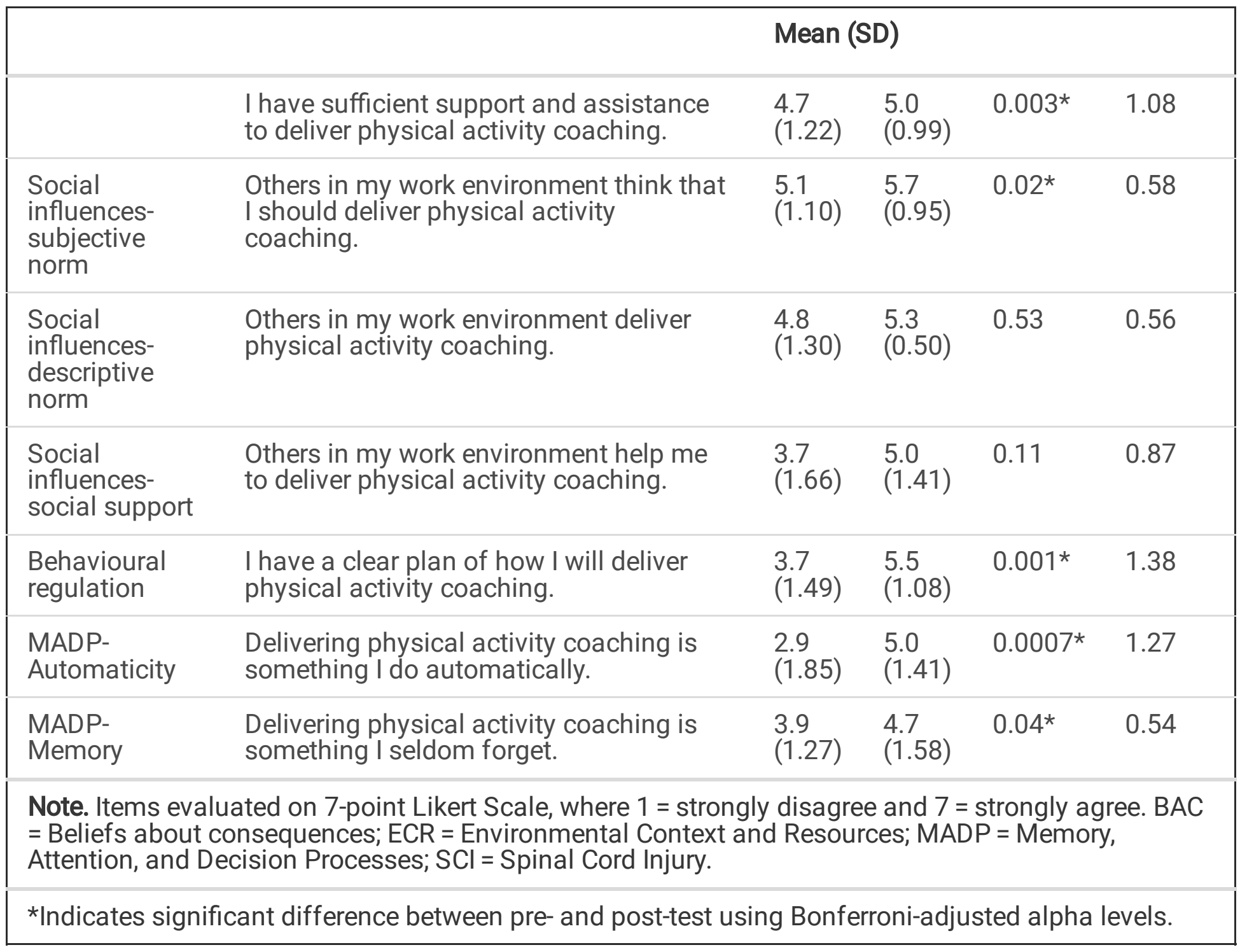

TDF domains including determinants that remained low (scored less than $5=$ slightly agree) at pretraining and observed no significant changes post-training were social/professional role and identity, beliefs about capabilities, environmental context and resources (innovation, organization, patient), and social influences - descriptive norm. Determinants within the beliefs about consequences reinforcement, goals, and social influences - social support domain did not show significant improvements, however effect sizes were moderate-large to very large.

\section{Discussion}

This study examined the effects of an implementation intervention on physical activity coaching behaviour and its determinants among interventionists using the ProACTIVE SCI intervention. Overall, participants did not show significant changes in physical activity coaching behaviour during the training practice period (between training 1 and 2). However, training improved physical activity coaching determinants in the TDF domains of knowledge, skills, beliefs about capabilities, environmental context and resources, social influences, behavioural regulation, and memory, attention and decision processes, signalling potential for improved physical activity coaching behaviour following the training. It is possible that the next phase of the implementation intervention may benefit from targeting the prioritization of 
physical activity (social/professional role and identity, goals), interventionist confidence to execute physical activity coaching effectively and under time constraints (beliefs about capabilities, environmental context and resources), and colleague physical activity coaching behaviour and support (social influences) to improve physical activity coaching behaviour change.

\section{Improvements in determinants: a signal for future physical activity coaching behaviour change}

Physical activity coaching behaviour was not improved during the practice period (i.e., the four weeks between the first and second day of training), however, improvements in TDF domains may signal potential for its future effectiveness in physical activity coaching behaviour change in the planned followup analyses at two and 6 months post-training (22). Similar changes in determinants have been linked with increases in physical activity coaching behaviour previously. For example, following an intervention that increased the delivery of physical activity promotion by nurses to cancer patients, improvements in physical activity coaching determinants congruent with the current study were observed. Specifically, changes within the Capability, Opportunity, Motivation-Behaviour model were assessed and similarly showed improvements in items that measured knowledge, skills, environmental context and resources, and social influences (28). Furthermore, in a Canadian national survey of physical activity prescription among physiotherapists $(n=239)$, beliefs about capabilities and environmental context and resources were of the most prevalent barriers to promoting physical activity to their clients, both of which showed improvements in the current study (9). An understanding of the needs of interventionists to deliver physical activity coaching is still evolving. Accordingly, researchers have called for the use of theory to understand factors that explain and maximize the effects of SCI peer-delivered physical activity interventions (29). Evaluating determinants of physical activity coaching delivery using the TDF shows potential for increased physical activity coaching behaviour at planned follow-up time points and helps to identify targets for improving the ongoing implementation intervention.

\section{Targeting determinants of physical activity coaching}

Examining TDF domains that remained low and were unchanged following training may help identify strategies for the next phase of the implementation intervention. Given the TDF domains requiring improvement in this study, strategies may include behavioural practice and the role of champions for promoting practice change. First, behavioural practice may improve self-efficacy to deliver physical activity coaching (Michie et al., 2018). According to social cognitive theory, mastery (which can be achieved through successful practice) is described as one of four sources of self-efficacy and is associated with intentions and ultimately behaviour change (31). As each individual's self-efficacy improves through behavioural practice, physical activity coaching behaviours may increase. Indeed, a study of over 400 physiotherapists demonstrated that self-efficacy is the best predictor of health promotion practice behaviours (32). Likewise, following training of $\mathrm{SCl}$ peer mentors to use brief action planning to promote physical activity, behavioural practice and feedback were identified as necessary intervention components to improve and maintain physical activity coaching skills (33). Although 
behavioural practice was a component of this study's implementation intervention, time restrictions limited practice to a 1-hour period. Thus, to address the TDF domains of beliefs about capabilities, more opportunities for behavioural practice may be needed.

Second, engaging champions to promote practice change may address social influences, beliefs about the priority of physical activity coaching, and perceptions of time constraint that were identified in the survey (30). Time is consistently identified as a primary factor limiting physical activity promotion among physiotherapists $(34,35)$. While shortening the intervention itself may be an option, an alternative target may be to transform interventionists' perceptions around the priority of delivering physical activity coaching $(35,36)$. Beliefs about the priority of physical activity promotion have been positively associated with the implementation of physical activity promotion by physical therapists and the time spent discussing physical activity by primary health care clinicians $(37,38)$. Champions may play an important role in facilitating this practice change (20). Their roles may include modelling physical activity coaching behaviours, leading ongoing implementation intervention components (e.g., refresher training, community of practice meetings), and actively encouraging their peers to do physical activity coaching. In another study looking at the implementation of a chronic care model, the presence of a team champion was associated with greater perceived team effectiveness, which in turn was associated with greater intervention uptake (e.g. greater number of changes made to improve chronic illness care) (39). Champion engagement may support interventionists to reframe viewing physical activity coaching as an integral part of all patient interactions, rather than as a time-consuming supplement, and help increase coaching behaviour uptake (36).

\section{Strengths and limitations}

As strengths, this study was underpinned in theory and involved the engagement of end-users throughout the intervention development process. Barriers were identified with a TDF-based survey, and frameworks (the KTA framework and QIF) were used to guide the adaptation of the intervention and its implementation in the local context $(16,20,23)$. Additionally, physiotherapists and peers with SCI were involved in the development of the research question, intervention design and delivery, identification of barriers to implementation, and selection of outcome measures. As limitations, the physical activity coaching behaviour results are only reflective of the first training session. As the participants completed the last survey immediately following the second training session, any practice reflective of the second training session occurred afterwards and was not evaluated due to a halt in data collection resulting from COVID-19. It is also possible that the 4-week practice period was an insufficient amount of time to see clients that were appropriate for physical activity coaching. Additionally, there was a lack of internal consistency in most domains across their respective items in both pre- and post-implementation scores. This lack of internal consistency possibly resulted from modifying the DIBQ and having too few items included for each domain, a decision that was made within the core research team to keep the survey a reasonable length. The sample of physiotherapists used to assess the psychometrics of the DIBQ may also explain the differences seen in internal consistency in the present study. Huijg et al. (2014) assessed the internal consistency reliability of the DIBQ amongst physiotherapists already delivering a physical 
activity intervention (our participants were not delivering a formal physical activity intervention at baseline) and target populations did not include people with $\mathrm{SCl}$. Though this means the conclusions that can be drawn about the physical activity coaching determinants data are limited to individual items, they were important for achieving the objectives of this study. Specifically, analyzing the data as individual items served the pragmatic purpose of identifying the specific supports required for the ongoing implementation intervention.

\section{Future directions}

Future directions for this work include evaluating the long-term effects of the implementation intervention on physical activity coaching behaviour and its determinants among interventionists and employing phase two of the implementation intervention based on the present results (22). Explicit testing is also needed to discern whether outcomes were further improved with the use of theory and integrated knowledge translation.

\section{Conclusions}

This study supports the utility of evaluating behavioural determinants throughout the implementation process to address strengths and gaps of the intervention. Improvements in physical activity coaching determinants signal the potential for changes in physical activity coaching behaviour as the implementation intervention progresses. In response to identified gaps, providing behavioural practice and engaging champions more actively will be used in the ongoing implementation intervention. Using both the Knowledge to Action Framework and the Quality Implementation Framework has demonstrated preliminary value in implementation intervention design and may be important for future rehabilitation and community sites implementing the ProACTIVE intervention.

\section{Declarations}

Ethics approval and consent to participate: Ethics approval for the protocol was granted by the Clinical Research Ethics Board at the University of British Columbia (H19-02694). We certify that appropriate consent was collected and all applicable institutional and governmental regulation concerning the ethical use of human volunteers were followed during the course of this research.

Consent for publication: Not applicable

Availability of data and materials: The datasets generated and/or analysed during the current study are available in the Additional files or from the corresponding author on reasonable request.

Competing Interests: The authors have no competing interests.

Funding: This work was supported a PRAXIS Grant (grant number G2020-21). Dr. Ma is supported by the Michael Smith Foundation for Health Research Trainee Award (\#17936), the Arthritis Society PostDoctoral Fellowship (TPF-18-0209), and the Canadian Institute of Health Research Post-Doctoral 
Fellowship (201910MFE-430114-231890). The funding source did not play a role in study design; in the collection, analysis and interpretation of data; in the writing of the report; or in the decision to submit the article for publication.

\section{Authors' contributions:}

HS: Contributed to study conceptualization, data collection, analysis, and writing of the manuscript.

KMG- Contributed to study conceptualization, analysis, and review of the manuscript.

CLCL: Contributed to study conceptualization, implementation, and review of the manuscript.

CM: Contributed to study conceptualization, implementation, and review of the manuscript.

KW: Contributed to study conceptualization, implementation, and review of the manuscript.

JKM- Contributed to study conceptualization, data collection, analysis, and writing of the manuscript.

Acknowledgements: We would like to thank Dr. Andrea Bundon for her generous time in reviewing the manuscript.

\section{References}

1. Hicks AL, Martin Ginis KA, Pelletier CA, Ditor DS, Foulon B, Wolfe DL. The effects of exercise training on physical capacity, strength, body composition and functional performance among adults with spinal cord injury : a systematic review. 2011;49(11):1103-27. Available from: http://dx.doi.org/10.1038/sc.2011.62.

2. Van Der Scheer JW, Martin Ginis KA, DItor DS, Goosey-Tolfrey VL, Hicks AL, West CR, et al. Effects of exercise on fitness and health of adults with spinal cord injury: A systematic review. Neurology. 2017;89(7):736-45.

3. Noreau L, Shephard RJ. Spinal Cord Injury, Exercise and Quality of Life. Vol. 20, Sports Medicine. Sports Med; 1995. pp. 226-50.

4. Fekete $\mathrm{C}$, Rauch A. Correlates and determinants of physical activity in persons with spinal cord injury : A review using the International Classification of Functioning, Disability and Health as reference framework. Disabil Health J [Internet]. 2012;5(3):140-50. Available from: http://dx.doi.org/10.1016/j.dhjo.2012.04.003.

5. Williams TL, Smith B, Papathomas A. The barriers, benefits and facilitators of leisure time physical activity among people with spinal cord injury: a meta-synthesis of qualitative findings. Health Psychol Rev [Internet]. 2014 Dec [cited 2014 Oct 4];8(4):404-25. Available from: http://www.ncbi.nlm.nih.gov/pubmed/25211208.

6. Van Den Berg-Emons RJ, Bussmann JB, Stam HJ. Accelerometry-based activity spectrum in persons with chronic physical conditions. Arch Phys Med Rehabil. 2010;91(12):1856-61. 
7. Garshick E, Kelley A, Cohen SA, Garrison A, Tun CG, Gagnon D, et al. A prospective assessment of mortality in chronic spinal cord injury. Spinal Cord. 2005 Jul;43(7):408-16.

8. Myers J. Exercise and Cardiovascular Health. 2003.

9. Ma JK, Cheifetz O, Todd KR, Chebaro C, Hoong S, Robert P, et al. Co-development of a physiotherapist-delivered physical activity intervention for adults with spinal cord injury. Spinal Cord. 2020.

10. Whiteneck G, Gassaway J, Dijkers M, Backus D, Charlifue S, Chen D, et al. Inpatient treatment time across disciplines in spinal cord injury rehabilitation. J Spinal Cord Med. 2011 Mar;34(2):133-48.

11. Letts L, Martin Ginis KA, Faulkner G, Colquhoun H, Levac D, Gorczynski P. Preferred methods and messengers for delivering physical activity information to people with spinal cord injury: a focus group study. Rehabil Psychol [Internet]. 2011;56(2):128-37. Available from: http://dx.doi.org/10.1037/a0023624.

12. Shirley D, van der Ploeg HP, Bauman AE. Physical activity promotion in the physical therapy setting: Perspectives from practitioners and students. Phys Ther. 2010 Sep;90(9):1311-22.

13. Gainforth HL, Giroux EE, Shaw RB, Casemore S, Clarke TY, McBride CB, et al. Investigating Characteristics of Quality Peer Mentors With Spinal Cord Injury. Arch Phys Med Rehabil. 2019;100(10):1916-23.

14. Ma JK, West CR, Martin Ginis KA. The effects of a patient and provider co-developed, behavioural physical activity intervention on physical activity, psychosocial predictors, and fitness in individuals with spinal cord injury: A randomized controlled trial. Sport Med [Internet]. 2019;49(7):1117-31. Available from: https://doi.org/10.1007/s40279-019-01118-5.

15. Tomasone JR, Flood SM, Ma JK, Scime NV, Burke SM, Sleeth L, et al. Physical activity selfmanagement interventions for adults with spinal cord injury: Part 1-A systematic review of the use and effectiveness of behavior change techniques. Psychol Sport Exerc [Internet]. 2018;37(January):274-85. Available from: https://doi.org/10.1016/j.psychsport.2018.01.012.

16. Graham ID, Logan J, Harrison MB, Straus SE, Tetroe J, Caswell W, et al. Lost in knowledge translation: time for a map? J Contin Educ Health Prof. 2006;26(1):13-24.

17. Kothari A, McCutcheon C, Graham ID. Defining integrated knowledge translation and moving forward: A response to recent commentaries. Vol. 6: International Journal of Health Policy and Management. Kerman University of Medical Sciences; 2017. pp. 299-300.

18. Graham ID, Kothari A, McCutcheon C. Moving knowledge into action for more effective practice, programmes and policy: protocol for a research programme on integrated knowledge translation. Implement Sci. 2018 Dec;13(1):22.

19. Strifler L, Cardoso R, McGowan J, Cogo E, Nincic V, Khan PA, et al. Scoping review identifies significant number of knowledge translation theories, models, and frameworks with limited use. $\mathrm{J}$ Clin Epidemiol. 2018;100:92-102.

20. Meyers DC, Durlak JA, Wandersman A. The Quality Implementation Framework: A Synthesis of Critical Steps in the Implementation Process. Am J Community Psychol. 2012;50(3-4):462-80. 
21. Meyers DC, Katz J, Chien V, Wandersman A, Scaccia JP, Wright A. Practical Implementation Science: Developing and Piloting the Quality Implementation Tool. Am J Community Psychol. 2012;50(34):481-96.

22. Ma JK, Walden K, McBride CB, Le Cornu Levett C, Colistro R, Plashkes T, et al. Implementation of the spinal cord injury exercise guidelines in the hospital and community settings: Protocol for a type II hybrid trial. Under Rev.

23. Cane J, O'Connor D, Michie S. Validation of the theoretical domains framework for use in behaviour change and implementation research. Implement Sci. 2012 Dec;7(1):37.

24. Huijg JM, Gebhardt WA, Dusseldorp E, Verheijden MW, van der Zouwe N, Middelkoop BJC, et al. Measuring determinants of implementation behavior: Psychometric properties of a questionnaire based on the theoretical domains framework. Implement Sci [Internet]. 2014;9(1):1-15. Available from: Implementation Science.

25. Michie S, Johnston M, Abraham C, Lawton R, Parker D, Walker A. Making psychological theory useful for implementing evidence based practice: A consensus approach. In: Quality and Safety in Health Care. 2005. p. 26-33.

26. Stirman SW, Baumann AA, Miller CJ. The FRAME. An expanded framework for reporting adaptations and modifications to evidence-based interventions. Implement Sci. 2019;14(1):1-10.

27. Stirman SW, Miller CJ, Toder K, Calloway A. Development of a framework and coding system for modifications and adaptations of evidence-based interventions. Implement Sci. 2013 Jun;8(1).

28. Webb J, Hall J, Hall K, Fabunmi-Alade R. Increasing the frequency of physical activity very brief advice by nurses to cancer patients. A mixed methods feasibility study of a training intervention. Public Health. 2016 Oct;139:121-33.

29. Martin Ginis KA, Nigg CR, Smith AL. Peer-delivered physical activity interventions: an overlooked opportunity for physical activity promotion.

30. Michie S, Carey RN, Johnston M, Rothman AJ, Bruin M, De, Kelly MP, et al. From theory-inspired to theory-based interventions: A protocol for developing and testing a methodology for linking behaviour change techniques to theoretical mechanisms of action. Ann Behav Med [Internet]. 2018; Available from: http://dx.doi.org/10.1007/s12160-016-9816-6.

31. Bandura A. Health promotion from the perspective of social cognitive theory. Psychol Health [Internet]. $1998 \mathrm{Jul} ; 13(4): 623-49$. Available from: http://www.tandfonline.com/doi/abs/10.1080/08870449808407422.

32. Rea BL, Marshak HH, Neish C, Davis N. The role of health promotion in physical therapy in California, New York, and Tennessee. Phys Ther. 2004;84(6):510-23.

33. Gainforth HL, Latimer-Cheung AE, Davis C, Casemore S, Martin Ginis KA. Testing the feasibility of training peers with a spinal cord injury to learn and implement brief action planning to promote physical activity to copy.pdf. J Spinal Cord Med. 2015;38(4):515-25.

34. McMahon N, Connolly C. Health promotion knowledge, attitudes and practices of chartered physiotherapists in Ireland: A national survey. Vol. 34, Physiotherapy Practice and Research. 2013. 
p. $21-8$.

35. Aweto HA, Oligbo CN, Fapojuwo OA, Olawale OA. Knowledge, attitude and practice of physiotherapists towards promotion of physically active lifestyles in patient management. BMC Health Serv Res. 2013 Dec;13(1):21.

36. Walkeden S, Walker KM. Perceptions of physiotherapists about their role in health promotion at an acute hospital: A qualitative study. Physiother (United Kingdom). 2015 Jun;101(2):226-31.

37. Laws RA, Kirby SE, Powell Davies GP, Williams AM, Jayasinghe UW, Amoroso CL, et al. "Should I and Can I?": A mixed methods study of clinician beliefs and attitudes in the management of lifestyle risk factors in primary health care. BMC Health Serv Res. 2008.

38. Huijg JM, Dusseldorp E, Gebhardt WA, Verheijden MW, van der Zouwe N, Middelkoop BJC, et al. Factors Associated With Physical Therapists' Implementation of Physical Activity Interventions in the Netherlands. Phys Ther. 2015 Apr;95(4):539-57.

39. Shortell SM, Marsteller JA, Lin M, Pearson ML, Wu SY, Mendel P, et al. The role of perceived team effectiveness in improving chronic illness care. Med Care. 2004;42(11):1040-8.

\section{Supplementary Files}

This is a list of supplementary files associated with this preprint. Click to download.

- Additionalfile1.docx

- Additionalfile2.xlsx

- Additionalfile3.pdf

- Additionalfile4.docx

- Additionalfile5TIDieRChecklist.docx

- Additionalfile6STROBEChecklist.docx 